Article

\title{
Computational Study of Sensitivity Enhancement in Surface Plasmon Resonance (SPR) Biosensors by Using the Inclusion of the Core-Shell for Biomaterial Sample Detection
}

\author{
Widayanti $^{1}$ (D), Kamsul Abraha ${ }^{2, *}$ and Agung Bambang Setio Utomo ${ }^{2}$ \\ 1 Department of Physics, Universitas Islam Negeri (UIN) Sunan Kalijaga, Yogyakarta 55281, Indonesia; \\ widayan76@gmail.com \\ 2 Department of Physics, Universitas Gadjah Mada, Sekip Utara, Yogyakarta 55281, Indonesia; \\ agungbambang@ugm.ac.id \\ * Correspondence: kamsul@ugm.ac.id
}

Received: 24 May 2018; Accepted: 1 August 2018; Published: 7 August 2018

\begin{abstract}
A theoretical analysis and computational study of biomaterial sample detection with surface plasmon resonance (SPR) phenomenon spectroscopy are presented in this work with the objective of achieving more sensitive detection. In this paper, a $\mathrm{Fe}_{3} \mathrm{O}_{4} @ \mathrm{Au}$ core-shell, a nanocomposite spherical nanoparticle consisting of a spherical $\mathrm{Fe}_{3} \mathrm{O}_{4}$ core covered by an $\mathrm{Au}$ shell, was used as an active material for biomaterial sample detection, such as for blood plasma, haemoglobin $(\mathrm{Hb})$ cytoplasm and lecithin, with a wavelength of $632.8 \mathrm{~nm}$. We present the detection amplification technique through an attenuated total reflection (ATR) spectrum in the Kretschmann configuration. The system consists of a four-layer material, i.e., prism $/ \mathrm{Ag} / \mathrm{Fe}_{3} \mathrm{O}_{4} @ \mathrm{Au}+$ biomaterial sample/air. The effective permittivity determination of the core-shell nanoparticle $\left(\mathrm{Fe}_{3} \mathrm{O}_{4} @ \mathrm{Au}\right)$ and the composite $\left(\mathrm{Fe}_{3} \mathrm{O}_{4} @ \mathrm{Au}\right.$ + biomaterial sample) was done by applying the effective medium theory approximation, and the calculation of the reflectivity was carried out by varying the size of the core-shell, volume fraction and biomaterial sample. In this model, the refractive index (RI) of the BK7 prism is 1.51; the RI of the Ag thin film is $0.13455+3.98651 i$ with a thickness of $40 \mathrm{~nm}$; and the RI of the composite is varied depending on the size of the nanoparticle core-shell and the RI of the biomaterial samples. Our results show that by varying the sizes of the core-shell, volume fraction and the RIs of the biomaterial samples, the dip in the reflectivity (ATR) spectrum is shifted to the larger angle of incident light, and the addition of a core-shell in the conventional SPR-based biosensor leads to the enhancement of the SPR biosensor sensitivity. For a core-shell with a radius $a=2.5 \mathrm{~nm}$, the sensitivity increased by $10 \%$ for blood plasma detection, $47.72 \%$ for $\mathrm{Hb}$ cytoplasm detection and by $22.08 \%$ for lecithin detection compared to the sensitivity of the conventional SPR-based biosensor without core-shell addition.
\end{abstract}

Keywords: biomaterial detection; SPR-based biosensors; computational study; $\mathrm{Fe}_{3} \mathrm{O}_{4} @ \mathrm{Au}$ core-shell

\section{Introduction}

Currently, there is increasing interest in the development of magnetic and plasmonic nanoparticles as active materials for biomolecule detection [1]. A new nanoparticle that combines multiple functions or properties has attracted considerable attention because of its revolutionary technology which enables the sensitivity enhancement of surface plasmon resonance (SPR)-based biosensors. The optical sensor based on SPR is one of the most sensitive methods for detecting biomolecules and works by detecting the changes of the material refractive index, having a fast response and real-time, bio-specific interaction analysis as well as being a label-free technique [2]. SPR is a physical process that occurs 
when the wave vector of the evanescent wave (EW) matches the wave vector of the surface plasmon (SP) under the total internal reflection condition. This resonance condition is expressed as

$$
\frac{\omega_{0}}{c} n_{p} \sin \theta_{\mathrm{SPR}}=\frac{\omega_{0}}{c}\left(\frac{\varepsilon_{m} n_{d}^{2}}{\varepsilon_{m}+n_{d}^{2}}\right)^{1 / 2}
$$

The variable on left hand side is the propagation constant of a light beam incident at a resonance angle $\theta_{\text {SPR }}$ through the light coupling device (prism) of a refractive index, $n_{p}$, while the right-hand is the propagation constant with $\varepsilon_{m}$ as real part of the metal permittivity and $n_{d}$ as the refractive index of a dielectric material or sensing medium. $\omega_{0}$ and $c$ are the light frequency and the speed of the light in a vacuum, respectively. The evanescent wave occurs at the metal-dielectric interface when a $p$-polarized wave passes a prism through a metallic layer into a dielectric media.

The wave vector of the evanescent wave is a function of refractive indices of the dielectric, metal and analyte, i.e., the sensing medium. Therefore, if there is a local change in the refractive index of the sensing medium near the metal surface, this will in turn lead to a change in the propagation constant of SP and in the angle of incidence of light in order to satisfy the resonance. When applying an SPR biosensor, the Kretschmann geometry [3] of attenuated total reflection (ATR) has been found to be very suitable for this sensing and has become the most widely used geometry in SPR biosensors. Mostly, the metallic layer that is used in SPR biosensor measurement consists of either gold or silver. The first demonstration of SPR-based sensors for bio-sensing was reported in 1983 by Liedberg et al. [4]. Several methods to enhance the sensitivity of SPR biosensors for detecting biomolecules have been explored for the detection of DNA hybridization [5], acetylcholinesterase [6], membrane protein [7] and human blood-group [8]. SPR can also be a potential candidate for bio-sensing other biological properties such as haemoglobin concentration.

Some research has indicated that the conventional SPR-based biosensor was not capable of sensing a small amount of biomolecules such as DNA, virus or bacteria [9] due to the poor attachment of biomolecules onto the metal surface, and the fact that the low concentrations involved are difficult to detect directly [10]. In addition, the changes in the refractive index of the medium [11] under a thin metal layer are very small. Therefore, the enhancement of sensitivity for detecting small biomolecules can be developed by several approaches, such as by adding a nanoparticle core-shell as the active material in the conventional SPR-based biosensor. Comparing with a nanoparticle with a spherical shape, the inclusion of a core-shell aims to avoid polar resonance [12] and to obtain the plasmonic wavelength by varying the radius of the core and the thickness of the shell. A core-shell was said to be a unique material since it is a combination of magnetic and plasmonic materials which have different optical properties to the core and the shell. Some studies have observed, either experimentally or theoretically, the optical properties of the core-shell when included in SPR-based biosensors. It is observed that the optical response or resonance spectrum of the core-shell depends on the size of the core and the thickness of the shell. Hence, the core-shell can be used to tune the plasmonic wavelength [13], e.g., for $\mathrm{AgSiO}_{2}$ [12], $\mathrm{TiO}_{2} @ \mathrm{Au}, \mathrm{TiO}_{2} @ \mathrm{Ag}$ [14] and $\mathrm{Fe}_{3} \mathrm{O}_{4} @ \mathrm{Au}$ [15]. The study of the optical response of an $\mathrm{Fe}_{3} \mathrm{O}_{4} @ A$ core-shell was performed by varying the radius of $\mathrm{Fe}_{3} \mathrm{O}_{4}$ and the thickness of $\mathrm{Au}$. There was a shift in the resonance spectrum due to the changes in the size of the core and the shell. The core $\mathrm{Fe}_{3} \mathrm{O}_{4}$ can make the biomolecule attachment easier with its magnetic properties, while the shell Au exhibits nontoxicity and compatible properties. Furthermore, the performance of the SPR-based biosensor can be enhanced by using the nanoparticle core-shell $\mathrm{Fe}_{3} \mathrm{O}_{4} @ A$ u rather than using only $\mathrm{Fe}_{3} \mathrm{O}_{4}$ or only Au. The presence of $\mathrm{Fe}_{3} \mathrm{O}_{4} @ \mathrm{Au}$ is also capable of enhancing the immobilization of biomolecules such as haemoglobin [16], as well as detecting antibody IgG [17] and detecting the DNA of chum salmon [18]. The inclusion of $\mathrm{Fe}_{3} \mathrm{O}_{4} @ \mathrm{Au}$ in the SPR-based biosensor was performed for the enhancement of the detection of thrombin [19] and the protein concentration of interleukin IL17 [20]. Detection of haemoglobin concentration has been explored by SPR-based biosensors for three 
wavelengths ( $401.5 \mathrm{~nm}, 589.3 \mathrm{~nm}$ and $706.5 \mathrm{~nm}$ ) with haemoglobin concentrations varying between 0 and $140 \mathrm{~g} / \mathrm{L}$ [21].

Due to the coating of the Au shell for the magnetic core, which protected it from oxidation and aggregation, the stabilization of the core-shell $\left(\mathrm{Fe}_{3} \mathrm{O}_{4} @ \mathrm{Au}\right)$ was obviously enhanced. In addition, the current SPR technology has a number of advantages; i.e., a high processing sensitivity and selectivity, being non-destructive, a large tunability from the visible into the infrared (IR) spectrum region, label-free analysis and being capable of real-time monitoring. SPR is a kind of electromagnetic resonance that exists when there is an interface between the metal and dielectric. This system has been used to sense various biomolecules [22,23]. This method is very sensitive to size, shape and the refractive index of the surrounding medium that keeps contact with the thin metal layer. When the biomolecule comes into contact with the metal thin film, it is adsorbed onto its surface and hence increases the refractive index at the interface, resulting in a change of their resonance angle.

In this paper, we have been investigating the ATR spectrum of four-multilayer biosensors based on an SPR system with $\mathrm{Fe}_{3} \mathrm{O}_{4} @ \mathrm{Au}$ core-shell addition to detect biology samples that play roles in the interaction of light and the tissue of the body, such as blood plasma, haemoglobin $(\mathrm{Hb})$ cytoplasm and lecithin. The magnetic properties of $\mathrm{Fe}_{3} \mathrm{O}_{4} @ \mathrm{Au}$ are not utilized in this work because we were not applied the external magnetic field. We concern at the $\mathrm{Fe}_{3} \mathrm{O}_{4} @ A u$ properties such as its dispersivity, easily to its fabrication and synthesis and biocompatible. The refractive indices of those biomaterial samples have been measured by total internal reflection [24]. The blood plasma delivers oxygen and nutrients to the cells of the organs of the body and also transports waste products to be excreted. $\mathrm{Hb}$ cytoplasm is the functional molecule in the erythrocytes, increasing oxygen carrying capacity. Lecithin is the fundamental component of the membrane lipid of cells. The different effective permittivity of $\mathrm{Fe}_{3} \mathrm{O}_{4} @ \mathrm{Au}+$ biomaterial composites leads to a change in the SPR resonance angle. This study was focused on the effects of the size of the core radius and shell thickness on the effective permittivity of $\mathrm{Fe}_{3} \mathrm{O}_{4} @$ Au by computational approximation. Also, we studied the effects of the volume fraction and the size of the core-shell on the composite effective permittivity and on the reflectivity of the SPR-based biosensor for biomaterial sample detection. Then, the enhancement of the sensitivity of SPR configuration was estimated.

\section{Materials and Methods}

\subsection{Kretschmann Configuration with Four Layers}

Here, we apply the analytical and computational approximation to calculate reflectivity in the attenuated total reflection (ATR) method and determined the effective permittivity of the composite (the mixture of $\mathrm{Fe}_{3} \mathrm{O}_{4} @ \mathrm{Au}$ and biomaterial embedded in water). In this study, we used the Kretschmann configuration [3] with four layers. I.e., prism/Ag/composite/air, shown in Figure 1. The angle $\theta_{i}$ and $\theta_{r}$ are the incident and the reflection angle, respectively, $k_{x}$ is the wave vector component along $x$-axis, and $d$ is the thickness of each layer.

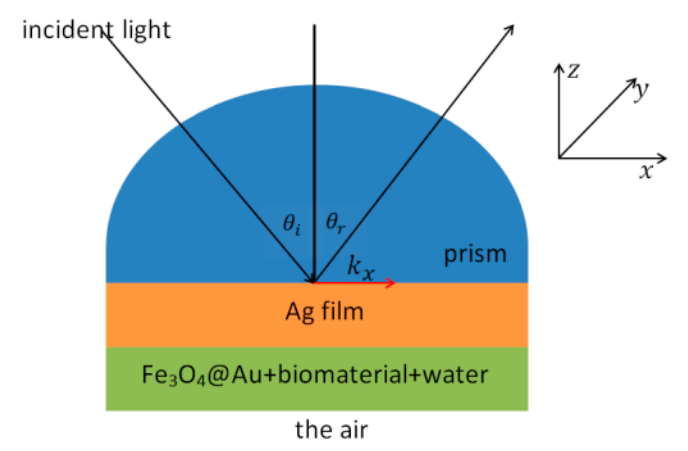

Figure 1. Kretschmann configuration for a surface plasmon resonance (SPR)-based biosensor with the inclusion of $\mathrm{Fe}_{3} \mathrm{O}_{4} @ \mathrm{Au}$ core-shell. 
Figure 2 shows the model of the composite layer containing the inclusion material $\left(\mathrm{Fe}_{3} \mathrm{O}_{4} @ \mathrm{Au}+\right.$ biomaterial samples) and the host material (water). The inclusion material consists of the scattered grain material $\left(\mathrm{Fe}_{3} \mathrm{O}_{4} @ \mathrm{Au}\right)$ and the interfacial shell material (biomaterial sample).

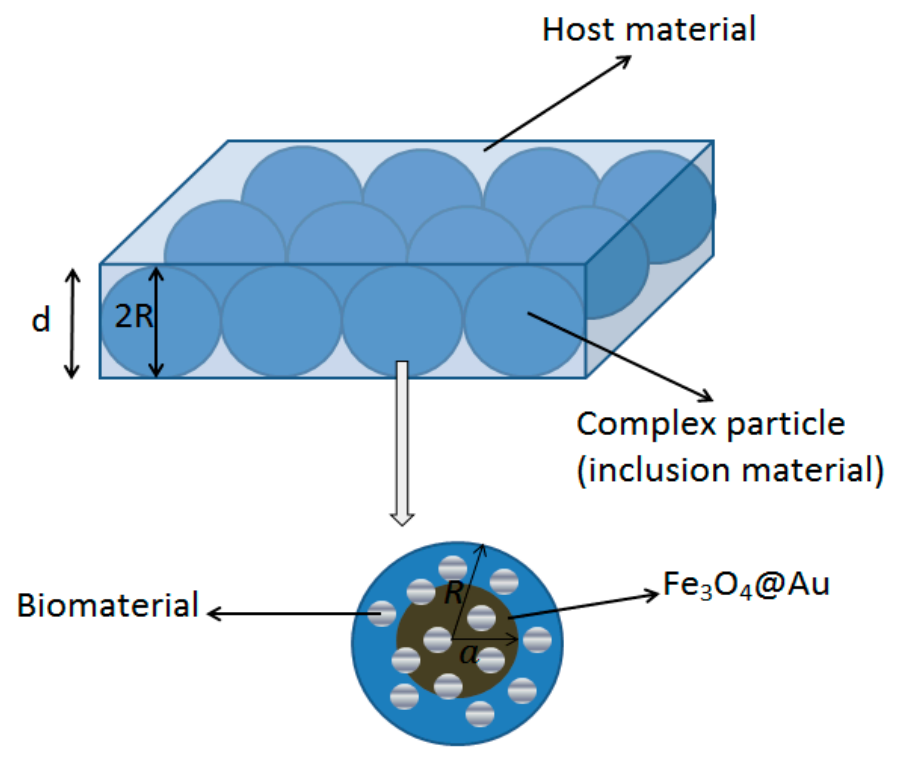

Figure 2. The composite model contains the complex particle (inclusion material) and the host material.

In this SPR configuration, the refractive index of the BK7 glass prism is 1.510, the wavelength of the electromagnetic wave is $632.8 \mathrm{~nm}$, the complex refractive index of silver $0.13455+3.98651 i$ [25], and the refractive index of biomaterial sample is varied. The refractive index of water and air is 1.33 and 1.0, respectively [9]. The thickness of the $\mathrm{Ag}$ film was $d=40 \mathrm{~nm}$, and the composite was $d=20 \mathrm{~nm}$. The ATR reflectivity $R$ is given by the Fresnel equation [26].

$$
R=\left|r_{i j k}\right|^{2}=\left|\frac{r_{i j}+r_{j k} e^{2 i k_{j z} d_{j}}}{1+r_{i j} r_{j k} e^{2 i k_{j z} d_{j}}}\right|^{2}
$$

with

$$
r_{i j}=\frac{k_{i} \varepsilon_{j}-k_{j} \varepsilon_{i}}{k_{i} \varepsilon_{j}+k_{j} \varepsilon_{i}}
$$

where $r_{i j}$ is the surface reflectivity coefficient between medium $i$ and medium $j . k_{i j}$ is the wave vector component perpendicular to the surface, $k_{x}$ is the wave vector component parallel to the surface, whereas $d_{j}$ and $\varepsilon_{i}$ are, respectively, the $j$-th layer thickness and the $i$-th medium dielectric constant.

\subsection{The Effective Permittivity of the Spherical Core-Shell}

Our simulation of the $\mathrm{Fe}_{3} \mathrm{O}_{4} @ \mathrm{Au}$ core-shell is performed on the model as shown in Figure 3. The magnetic nanoparticle core-shell consists of an $\mathrm{Fe}_{3} \mathrm{O}_{4}$ core of radius $b$ coated by a metallic Au of thickness $(a-b)$. The dielectric constants of the magnetic nanoparticle and the metallic Au are $\varepsilon_{c}$, and $\varepsilon_{s}$, respectively. The dielectric constants of the materials are dependent on their refractive indices. 


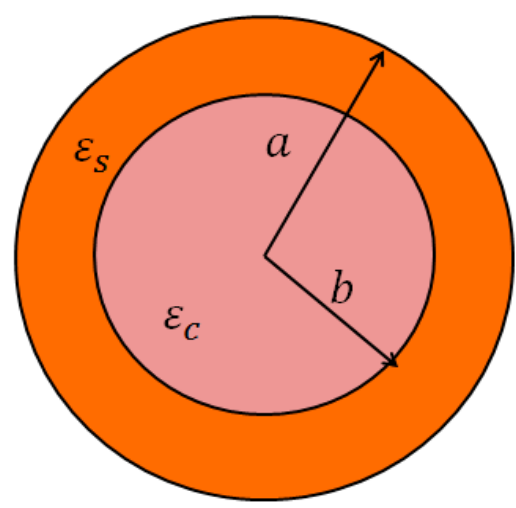

Figure 3. The model of the nanoparticle $\mathrm{Fe}_{3} \mathrm{O}_{4} @ \mathrm{Au}$ core-shell.

The value of complex $\varepsilon_{\mathcal{C}}$ is adopted from Schlegel [27] through reflectivity measurement and the Kramers-Kronig relation, and $\varepsilon_{s}$ can be quoted from the work by Johnson and Christy [25]. The effective permittivity $\left(\varepsilon_{\text {eff }}\right)$ of the $\mathrm{Fe}_{3} \mathrm{O}_{4} @$ Au core-shell is derived from the internal homogenization for plasmonic and dielectric constituent materials [28], namely

$$
\varepsilon_{\text {eff }}=\varepsilon_{s} \frac{a^{3}\left(\varepsilon_{c}+2 \varepsilon_{s}\right)+2 b^{3}\left(\varepsilon_{c}-\varepsilon_{s}\right)}{a^{3}\left(\varepsilon_{c}+2 \varepsilon_{s}\right)-b^{3}\left(\varepsilon_{c}-\varepsilon_{s}\right)}
$$

\subsection{The Effective Permittivity of the Composite}

The effective permittivity of the composite $\left(\varepsilon_{\text {effc }}\right)$ is calculated by neglecting the correlation between the inclusion material (complex material or $\mathrm{Fe}_{3} \mathrm{O}_{4} @ \mathrm{Au}+$ biomaterial sample) and host material (water) using the Maxwell Garnett formula [29]:

$$
(1-F) \frac{\varepsilon_{\mathrm{effc}}-\varepsilon_{m}}{2 \varepsilon_{\mathrm{effc}}+\varepsilon_{m}}+F\left(\frac{\varepsilon_{\mathrm{effc}}-\varepsilon_{n}}{\varepsilon_{\mathrm{effc}}+\varepsilon_{n}}\right)=0
$$

with

$$
\varepsilon_{n}=\varepsilon_{1} \frac{\left(2 \varepsilon_{1}+\varepsilon_{2}\right)+2 \alpha\left(\varepsilon_{2}-\varepsilon_{1}\right)}{\left(2 \varepsilon_{1}+\varepsilon_{2}\right)-\alpha\left(\varepsilon_{2}-\varepsilon_{1}\right)}
$$

where $\alpha=\left(\frac{a}{R}\right)^{3}, a$ is the radius of $\mathrm{Fe}_{3} \mathrm{O}_{4} @ \mathrm{Au}, R$ is the radius of the complex particle $\left(\mathrm{Fe}_{3} \mathrm{O}_{4} @ \mathrm{Au}+\right.$ biomaterial sample), $F$ is the volume fraction of the inclusion material to the host material, $\varepsilon_{n}$ is the dielectric constant of the complex particle and $\varepsilon_{m}$ is the dielectric constant of the host material. $\varepsilon_{1}$ is the biomaterial sample dielectric constant as the interfacial shell, while $\varepsilon_{2}$ is the dielectric constant of the scattered grain $\left(\mathrm{Fe}_{3} \mathrm{O}_{4} @ \mathrm{Au}\right.$ core-shell). In this condition $\varepsilon_{2}=\varepsilon_{\text {eff }}$ in the Equation (4).

\subsection{Sensitivity from ATR Spectrum}

The calculation of the sensitivity of the SPR-based biosensor is written as [30]

$$
S=\frac{\Delta \theta_{\mathrm{SPR}}}{\Delta n}
$$

where $\Delta \theta_{\text {SPR }}$ is the difference in the SPR angle and $\Delta n$ is the change in refractive index. Whereas the sensitivity enhancement can be obtained from the relation

$$
\Delta S=\frac{S_{\text {core-shell }}-S_{\text {no core-shell }}}{S_{\text {no core-shell }}} \times 100 \%
$$

where $S_{\text {core-shell }}$ is the sensitivity of the conventional system (prism/Ag/biomaterial sample/air), $S_{\text {no core-shell }}$ is the sensitivity of the proposed system (prism/ $\mathrm{Ag} / \mathrm{Fe}_{3} \mathrm{O}_{4} @ \mathrm{Au}+$ biomaterial sample/air). 


\section{Results and Discussion}

The changes of the radius of the $\mathrm{Fe}_{3} \mathrm{O}_{4}$ core and the thickness of the Au shell lead to changes in the effective permittivity of the $\mathrm{Fe}_{3} \mathrm{O}_{4} @ \mathrm{Au}$ core-shell, while the change of the inclusion material to the host material leads to a change in the effective permittivity of the composite. Therefore, if the complex particle is applied to the SPR-based biosensor system, this change leads to the enhancement of the sensitivity of this biosensor. We can show from the reflectivity spectrum that the resonant angle shifts to the right.

Table 1 shows the effective permittivity of the core-shell (Equation (4)) for variations in the shell thickness. Table 2 shows the effective permittivity of the core-shell for variations in the core radius, and Table 3 shows the effective permittivity of the core-shell for $f=(b / a)^{3}$ variation. The data in Tables 1-3 are presented in Figures 4-6, respectively.

Table 1. The effective permittivity of an $\mathrm{Fe}_{3} \mathrm{O}_{4} @ \mathrm{Au}$ core-shell for variations of shell thickness. Imag: imaginary.

\begin{tabular}{ccccc}
\hline $\boldsymbol{b}(\mathbf{n m})$ & $\boldsymbol{a}(\mathbf{n m})$ & Shell Thickness (nm) & $f=(\boldsymbol{b} / \boldsymbol{a})^{\mathbf{3}}$ & $\begin{array}{c}\boldsymbol{\varepsilon}_{\text {eff }} \\
\text { (Real, Imag) }\end{array}$ \\
\hline 10 & 11 & 1 & 0.75 & $1.0092,3.2011$ \\
10 & 13 & 3 & 0.46 & $-2.5021,3.0123$ \\
10 & 15 & 5 & 0.30 & $-4.8721,2.6948$ \\
10 & 17 & 7 & 0.20 & $-6.4556,2.3952$ \\
10 & 20 & 10 & 0.13 & $-7.9297,2.0516$ \\
10 & 30 & 20 & 0.03 & $-9.7428,1.5407$ \\
10 & 40 & 30 & 0.02 & $-10.212,1.3921$ \\
10 & 100 & 90 & 0.001 & $-10.539,1.2845$ \\
\hline
\end{tabular}

Table 2. The effective permittivity of an $\mathrm{Fe}_{3} \mathrm{O}_{4} @ \mathrm{Au}$ core-shell for variations of core radius.

\begin{tabular}{cccc}
\hline $\boldsymbol{b}(\mathbf{n m})$ & $\boldsymbol{a}(\mathbf{n m})$ & $\boldsymbol{f}=(\boldsymbol{b} / \boldsymbol{a})^{\mathbf{3}}$ & $\begin{array}{c}\boldsymbol{\varepsilon}_{\text {eff }} \\
(\text { Real, Imag) }\end{array}$ \\
\hline 10 & 11 & 0.75 & $1.0092,3.2011$ \\
12 & 13 & 0.78 & $1.3637,3.2017$ \\
14 & 15 & 0.81 & $1.6230,3.2000$ \\
16 & 17 & 0.83 & $1.8209,3.1975$ \\
18 & 19 & 0.85 & $1.9768,3.1947$ \\
20 & 21 & 0.86 & $2.1028,3.1921$ \\
100 & 101 & 0.97 & $3.0427,3.1587$ \\
\hline
\end{tabular}

Table 3. The effective permittivity of an $\mathrm{Fe}_{3} \mathrm{O}_{4} @ \mathrm{Au}$ core-shell for variations of $f=(b / a)^{3}$.

\begin{tabular}{cccc}
\hline $\boldsymbol{b}(\mathbf{n m})$ & $\boldsymbol{a}(\mathbf{n m})$ & $f=(\boldsymbol{b} / \boldsymbol{a})^{\mathbf{3}}$ & $\begin{array}{c}\boldsymbol{\varepsilon}_{\text {eff }} \\
(\text { Real, Imag) }\end{array}$ \\
\hline 9.5 & 10 & 0.85 & $2.04008,3.19339$ \\
9.0 & 10 & 0.73 & $0.77837,3.19889$ \\
8.5 & 10 & 0.61 & $-0.49070,3.16118$ \\
8.0 & 10 & 0.51 & $-1.74550,3.08115$ \\
7.5 & 10 & 0.42 & $-2.96636,2.96227$ \\
7.0 & 10 & 0.34 & $-4.13333,2.81043$ \\
6.5 & 10 & 0.27 & $-5.22780,2.63368$ \\
\hline
\end{tabular}

Figure 4 shows that the increasing shell thickness for a fixed core radius $(10 \mathrm{~nm})$ leads to the decreasing of the real and imaginary part of the core-shell's effective permittivity. However, the real part tends to be constant at the shell thickness above $30 \mathrm{~nm}$. 


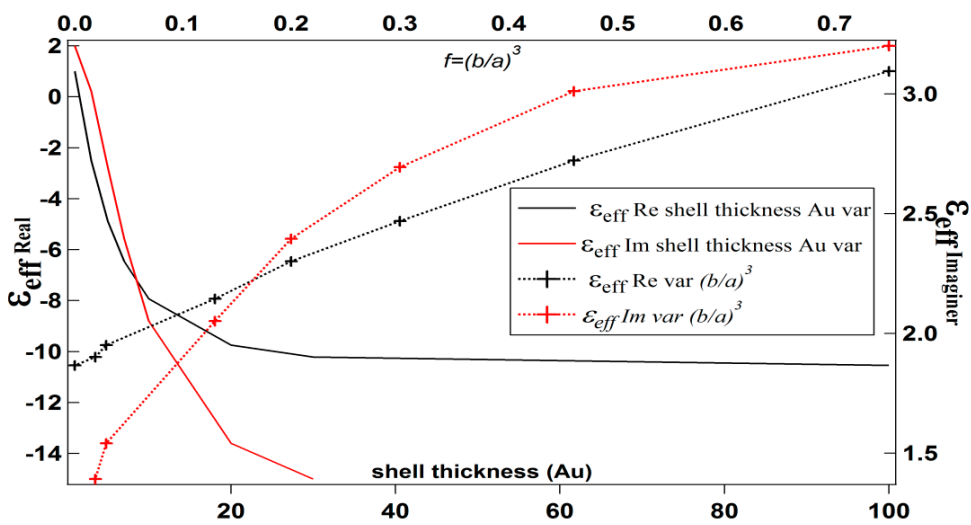

Figure 4. The effective permittivity of a core-shell for variations of shell thickness and $f=(b / a)^{3}$.

Figure 5 shows that increasing the core radius for a fixed shell thickness $(1 \mathrm{~nm})$ leads to an increase in the real part of the core-shell's effective permittivity while the imaginary part tends to be constant.

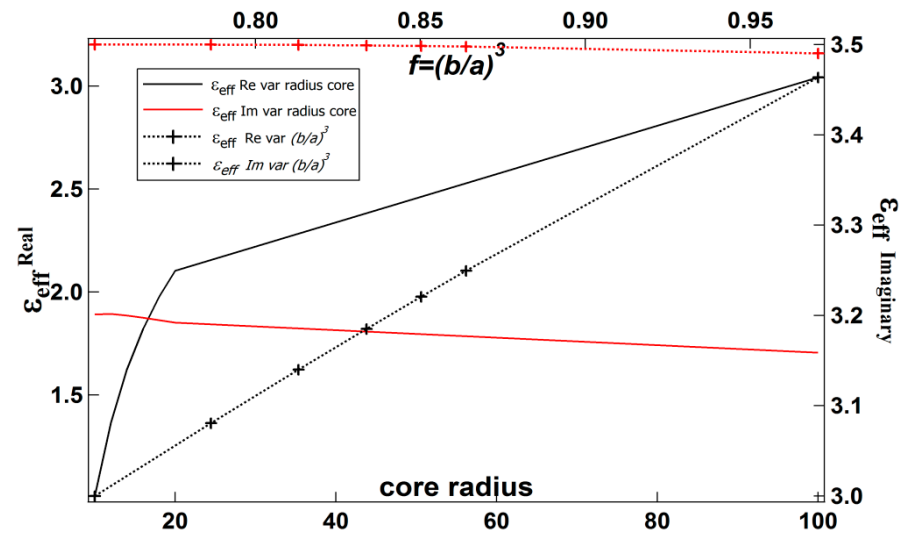

Figure 5. The effective permittivity of a core-shell for variations of the radius of the core and $f=(b / a)^{3}$.

If the core-shell's permittivity is viewed only from the $f=(b / a)^{3}$ variation, it shows that the increase of $f=(b / a)^{3}$ leads to an increase in the real and imaginary parts of the effective permittivity (Figure 6). Different radii of core-shell $(a=5 \mathrm{~nm})$ with the same $f=(b / a)^{3}$ variation shows the same effective permittivity value. Then, the effective permittivity of the composite can be obtained from Equation (5).

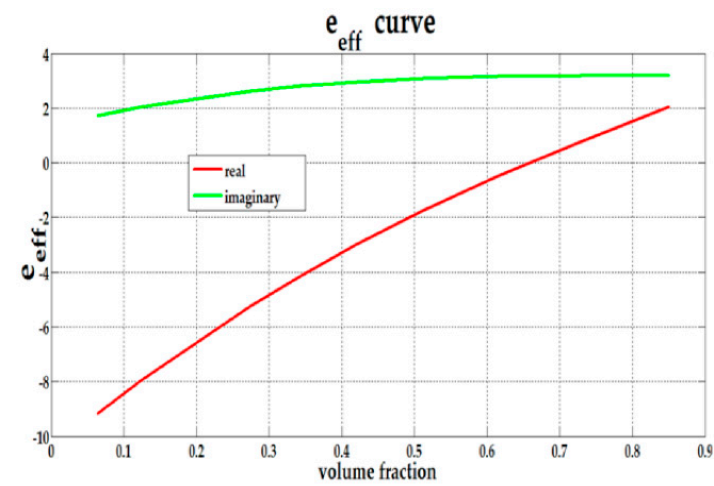

Figure 6. The effective permittivity of a core-shell for variations of $f=(b / a)^{3}$.

The thicknesses of the Ag metal in this SPR system is the other parameter that must be carefully controlled in order to obtain optimum performance for surface plasmon excitation. Therefore, 
the choice of the metal thickness is of utmost importance. In the configuration of SPR biosensor is prism $/ \mathrm{Ag} / \mathrm{Fe}_{3} \mathrm{O}_{4} @ \mathrm{Au}+$ biomaterial sample/air, by varying the Ag thickness, the ATR spectrum shows where the Ag metal film thickness yields the most desirable resonance peak. As the Ag thickness increases $(50-60 \mathrm{~nm})$, the depth of the resonance peak decreases. This indicates a reduced coupling efficiency of light into the SP mode on the film. This is due to the fact that the metal begins to act as a reflectance plane when its thickness increases to a point where light cannot couple into the surface charge oscillations that make up the plasmon mode; whereas if the Ag thin film is very thin (20-30 nm), this results in more coupling into the SP mode, but the amplitude of the evanescent wave that penetrated to dielectric materials on the metal layer is higher than the amplitude of the surface plasmon that generated from metal, the sensitivity was reduced. Obviously, from these effects, a compromise must be reached to obtain a satisfactory SPR system. Figure 7 was shows the optimal thickness to support an SPR system determined to lie at $40 \mathrm{~nm}$. From other literature, we get the standard of the thickness of the metal is in the range $40-50 \mathrm{~nm}$.

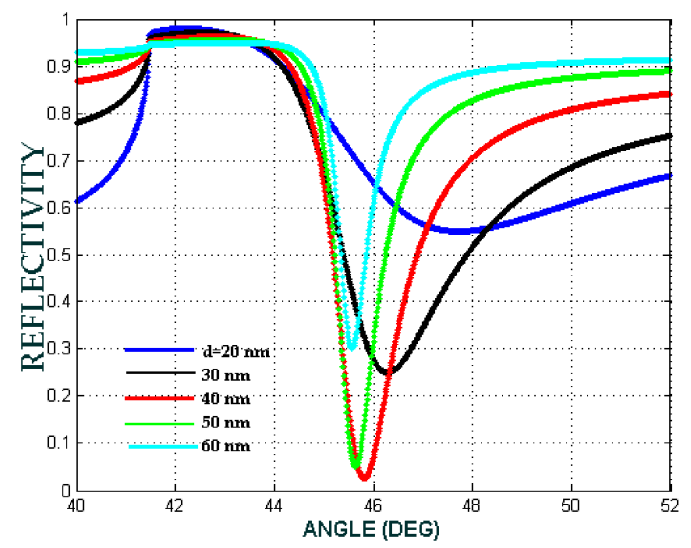

Figure 7. The attenuated total reflection (ATR) spectra for Ag metal thicknesses varying from $20 \mathrm{~nm}$ to $60 \mathrm{~nm}$ with the SPR biosensor configuration prism/ $\mathrm{Ag} / \mathrm{Fe}_{3} \mathrm{O}_{4} @ \mathrm{Au}+$ biomaterial sample/air at $a=2.5 \mathrm{~nm}$, the biomaterial sample is $\mathrm{Hb}$ cytoplasm with RI 1.3800 and $F=0.1$.

Based on the above results, we can choose the values of the core radii, the shell thickness and the ratio of the core to the core-shell radii $f=(b / a)^{3}$ to obtain the desirable effective permittivity of the $\mathrm{Fe}_{3} \mathrm{O}_{4} @ \mathrm{Au}$ core-shell. Figure 8 shows that the desirable effective permittivity is obtained at $f=0.85$ and $f=0.73$. For the presented model, we chose the moderate value of $f=0.73$ for reflectivity calculation because the shell is very thin for $f=0.85$.

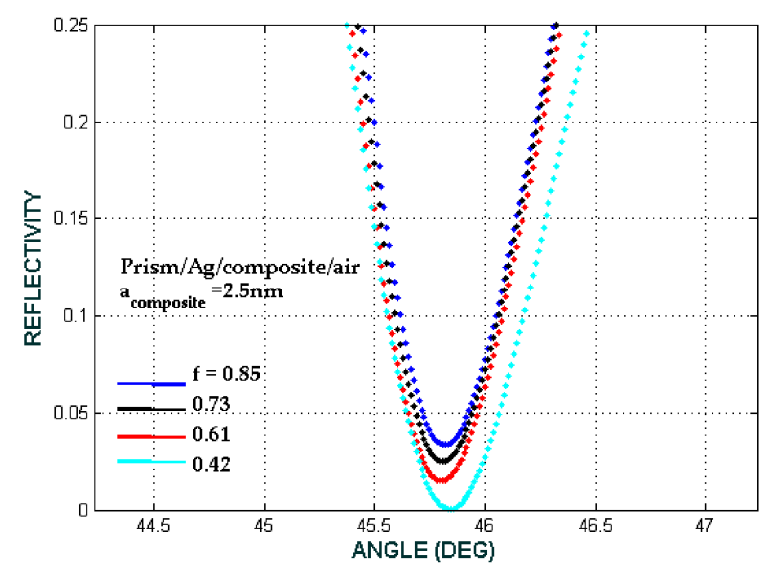

Figure 8. The ATR spectra with variations of $f=(b / a)^{3}$ with the SPR biosensor configuration prism/Ag/ $\mathrm{Fe}_{3} \mathrm{O}_{4} @ \mathrm{Au} /$ air $(a=2.5 \mathrm{~nm})$. 
Figures 9 and 10 shows the effective permittivity of the composite (inclusion material) with volume fraction $(F)$ variation given by the size variation of the core-shell $a$ from $2.5 \mathrm{~nm}$ to $10 \mathrm{~nm}$ for the chosen fixed $f=(b / a)^{3}=0.73$. Here, $F$ is the ratio between the amount of the inclusion material to the host material.

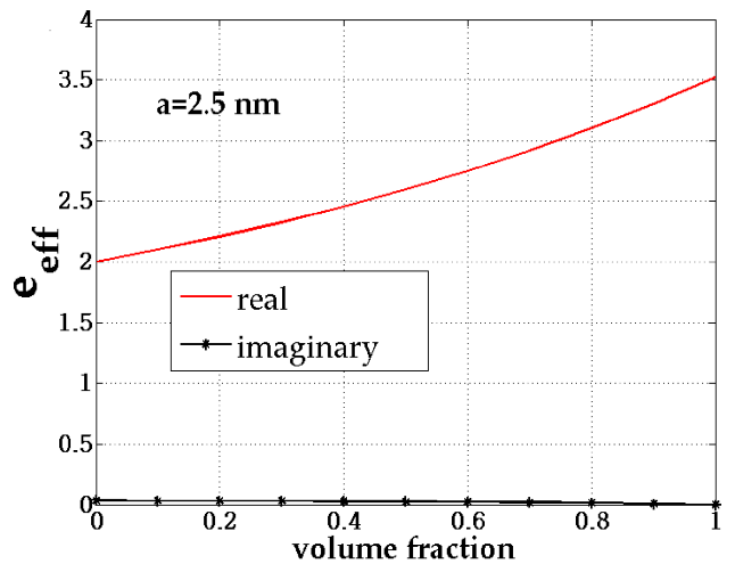

(a)

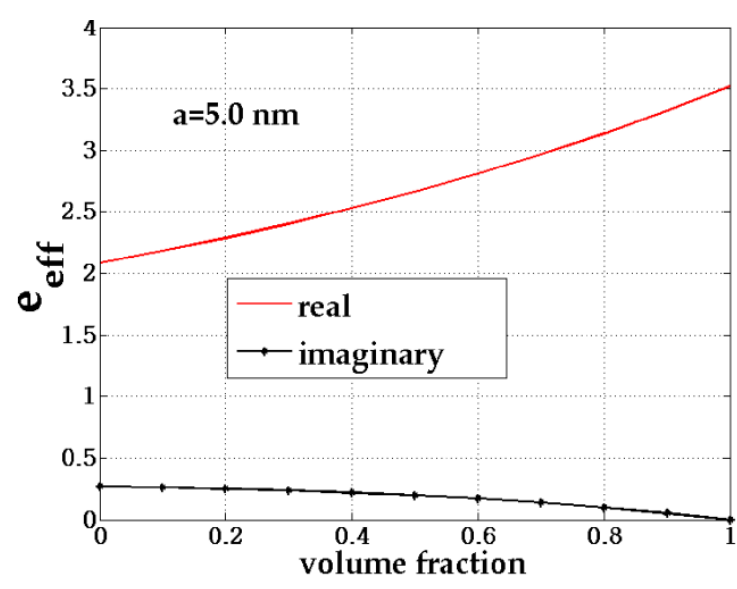

(b)

Figure 9. The composite effective permittivity with variations in the volume fraction $(F)$ of the composite for the fixed size of the core-shell of (a) $2.5 \mathrm{~nm}$ and (b) $5.0 \mathrm{~nm}$.

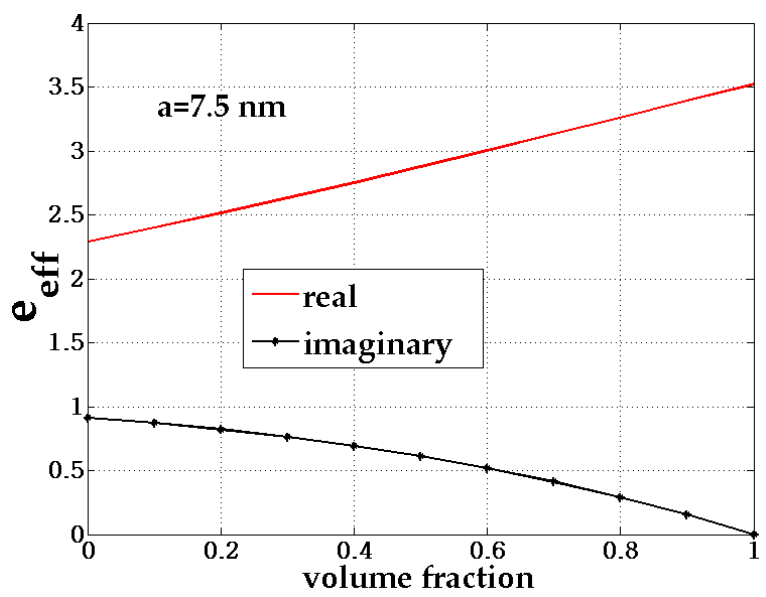

(a)

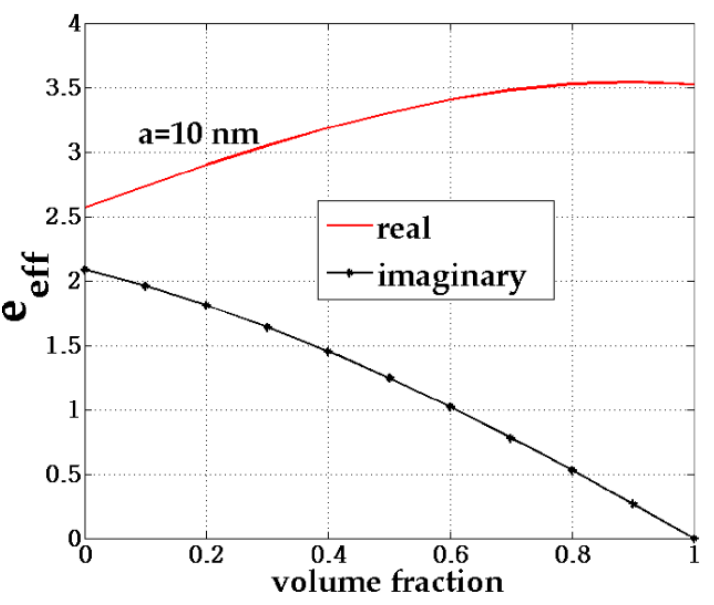

(b)

Figure 10. The composite effective permittivity with variations in the volume fraction $(F)$ of the composite for the fixed size of the core-shell of (a) $7.5 \mathrm{~nm}$ and (b) $10 \mathrm{~nm}$.

The reflectivity from the SPR-based biosensor consisting of a nanoparticle core-shell is shown in Figures 11 and 12. If the layers only consist of prism/Ag/Hb cytoplasm/air (conventional SPR), the dip of the ATR curve occurs at the incident angle $45.44^{\circ}$ (black line). After the composite had been deposited on to the surface of the Ag thin film, the dip of the reflectivity curve was shifted to a larger angle. Referring to Figure 11 for the volume fraction $(F)=0.1$ and the $\mathrm{Fe}_{3} \mathrm{O}_{4} @$ Au radii $(a)$ varying from $2.5 \mathrm{~nm}$ to $10 \mathrm{~nm}$, the SPR angle was shifted to a larger angle. By increasing the radii of $\mathrm{Fe}_{3} \mathrm{O}_{4} @ \mathrm{Au}$, the angle of resonance increases as well. It can be seen in Figure 11 that the minimum reflectivity are seen at $45.86^{\circ}$ for core-shell radii $2.5 \mathrm{~nm}$, while from Figure 12 , for the volume fraction $(F)=0.8$ and the $\mathrm{Fe}_{3} \mathrm{O}_{4} @ \mathrm{Au}$ radii varying from $2.5 \mathrm{~nm}$ to $10 \mathrm{~nm}$, the SPR angle is shifted to a larger angle as well. The figure shows that the minimum reflectivity occurred at $47.40^{\circ}$ for core-shell radii of $5 \mathrm{~nm}$ and at $47.55^{\circ}$ for radii of $7.5 \mathrm{~nm}$. 


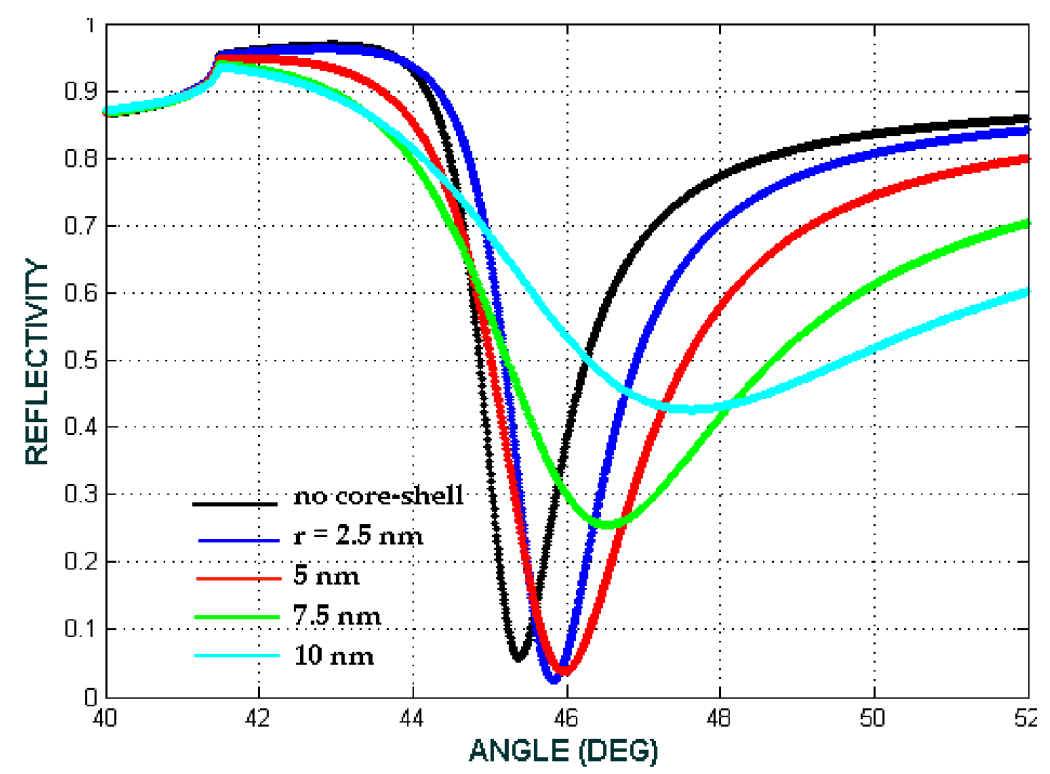

Figure 11. The ATR spectra for the volume fraction of the composite $F=0.1$. The radii of the core-shell varied from $2.5 \mathrm{~nm}$ to $10 \mathrm{~nm}$ with a fixed $(b / a)^{3}=0.73$ (biomaterial sample is $\mathrm{Hb}$ cytoplasm with a refractive index of 1.3871 or the concentration $\left.12.93 \mathrm{mmol} \mathrm{L}^{-1}\right)$.

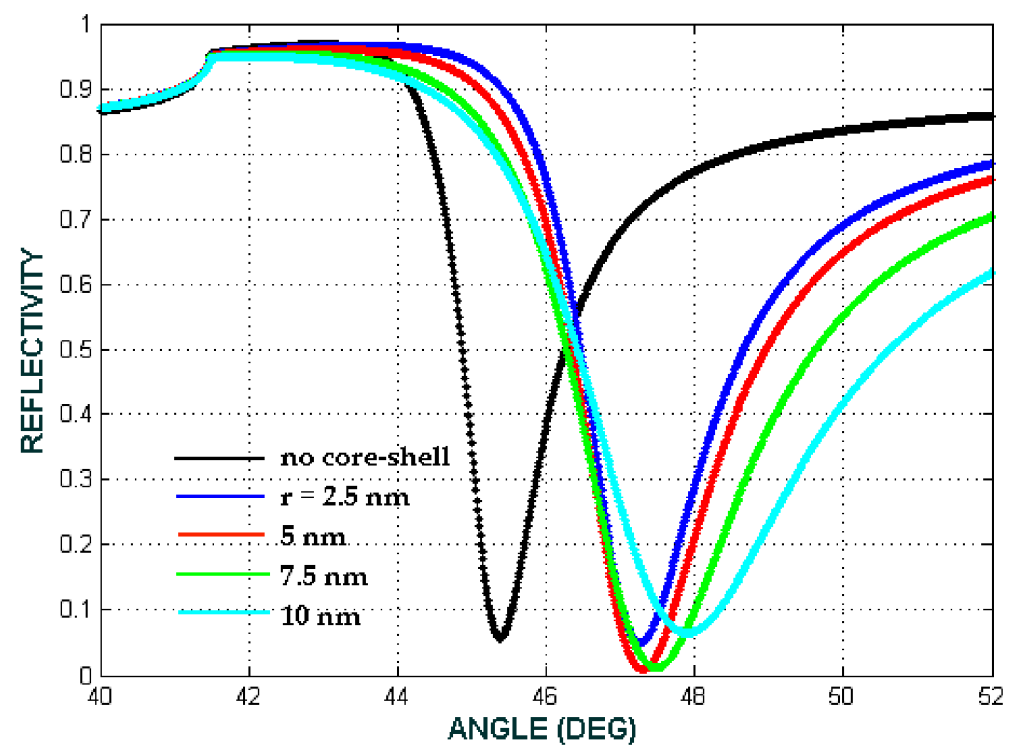

Figure 12. The ATR spectra for the volume fraction of the composite $F=0.8$. The radius of the core-shell varied from $2.5 \mathrm{~nm}$ to $10 \mathrm{~nm}$ with a fixed $(b / a)^{3}=0.73$ (biomaterial sample is $\mathrm{Hb}$ cytoplasma with a refractive index of 1.3871 or the concentration $12.93 \mathrm{mmol} \mathrm{L}^{-1}$ ).

In this presented model, biomaterial samples are blood plasma, $\mathrm{Hb}$ cytoplasm and lecithin with RIs of $1.3479,1.3800$ and 1.4838 , respectively. Figures 13-15 show the comparison of the angular shift of the SPR angle for three different configuration respectively. 


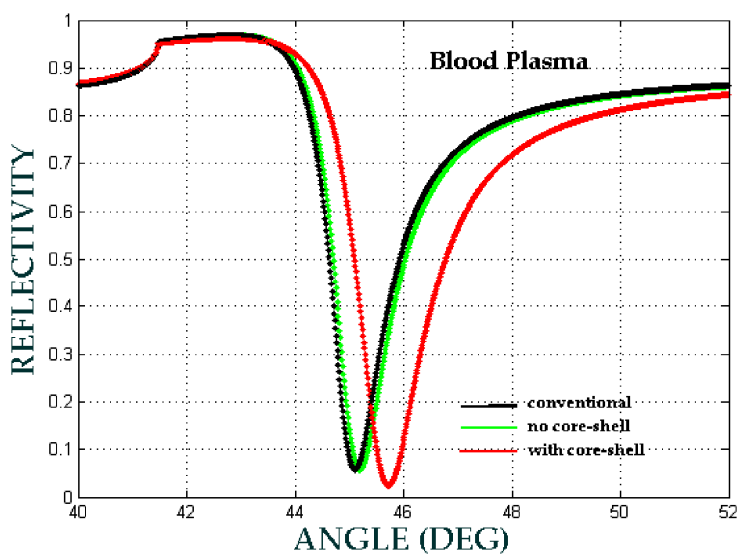

Figure 13. The ATR spectra for different configuration with the volume fraction of the composite $F=0.1$, the size of the core-shell $a=2.5 \mathrm{~nm}$ and $f=0.73$. (conventional: Prism/Ag/water/air, no core-shell: Prism/Ag/blood plasma + water/air, with core-shell: Prism/Ag/ $\mathrm{Fe}_{3} \mathrm{O}_{4} @ \mathrm{Au}+\mathrm{blood}$ plasma + water/air).

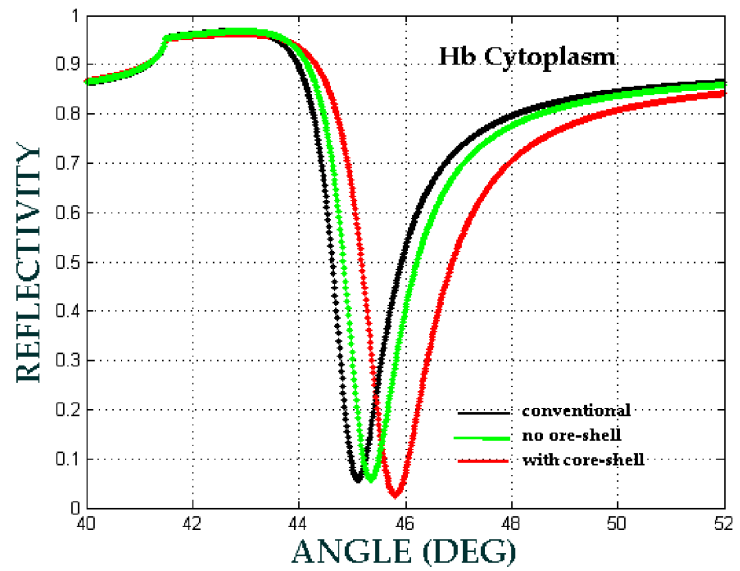

Figure 14. The ATR spectra for different configuration with the volume fraction of the composite $F=0.1$, the size of the core-shell $a=2.5 \mathrm{~nm}$ and $f=0.73$. (conventional: Prism/Ag/water/air, no core-shell: Prism/Ag/Hb Cytoplasm + water/air, with core-shell: Prism/Ag/ $\mathrm{Fe}_{3} \mathrm{O}_{4} @ \mathrm{Au}+\mathrm{Hb}$ cytoplasm + water/air).

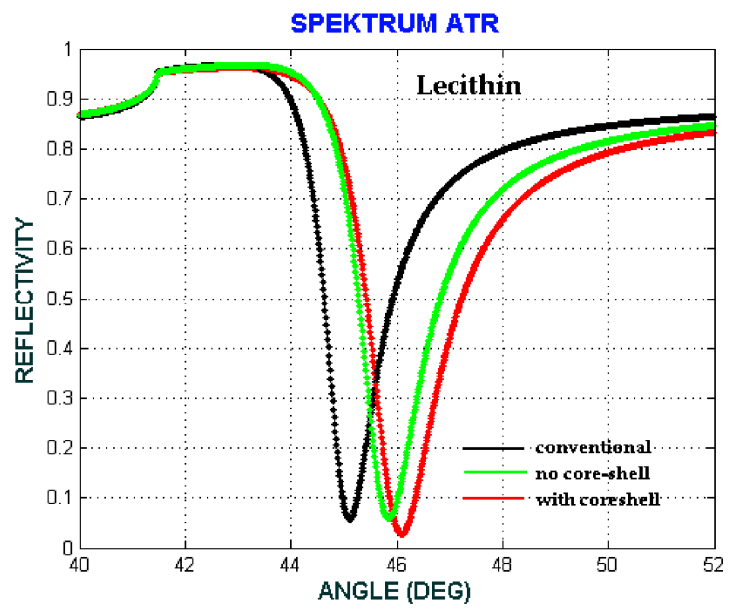

Figure 15. The ATR spectra for different configuration with the volume fraction of the composite $F=0.1$, the size of the core-shell $a=2.5 \mathrm{~nm}$ and $f=0.73$. (conventional: Prism/Ag/water/air, no core-shell: Prism/Ag/Lecithin + water/air, with core-shell: Prism/Ag/ $/ \mathrm{Fe}_{3} \mathrm{O}_{4} @ \mathrm{Au}+$ Lecithin + water/air). 
The angular shift of SPR angle have been showed at Table 4, where $\Delta \theta_{1}$ is the angular shift between no core-shell configuration with the conventional configuration, whereas $\Delta \theta_{2}$ is the angular shift between with core-shell configuration and no core-shell configuration.

Table 4. Angular shit of SPR angle for different biomaterial sample detection.

\begin{tabular}{cccc}
\hline Biomaterial Sample & $\boldsymbol{\Delta} \boldsymbol{\theta}_{1}($ degree $)$ & $\boldsymbol{\Delta} \boldsymbol{\theta}_{2}($ degree $)$ & $\boldsymbol{\Delta} \boldsymbol{\theta}=\boldsymbol{\theta}_{2}-\boldsymbol{\theta}_{1}($ degree $)$ \\
\hline Blood Plasma & 0.05 & 0.50 & 0.55 \\
Hb Cytoplasm & 0.21 & 0.44 & 0.65 \\
Lecithin & 0.71 & 0.77 & 0.94 \\
\hline
\end{tabular}

We can see that the angular shift for with core-shell configuration is higher than the angular shift for no core-shell configuration. Therefore, we can say that the involvement of Fe3O4@Au core-shell enhance the sensitivity of biomaterial detection.

Therefore, the sensitivity and the sensitivity enhancement can be obtained from Equations (7) and (8) respectively that, the sensitivity enhancement is $10 \%$ for blood plasma, $47.72 \%$ for $\mathrm{Hb}$ cytoplasm and $22.08 \%$ for lecithin. The selectivity of the SPR sensor is shown in Figures 13-15, in which each biomaterial sample RI value has a unique SPR angle. An increase in RI leads to an increase of the SPR angle. According to these results, the SPR phenomenon sensor with the core-shell addition can be used to selectively and sensitively detect biomaterial samples.

\section{Conclusions}

In summary, we have presented a theoretical analysis and computational study of the effect of the inclusion of a $\mathrm{Fe}_{3} \mathrm{O}_{4} @ \mathrm{Au}$ core-shell to enhance the sensitivity of an SPR-based biosensor through ATR spectra investigation (the magnetic properties of $\mathrm{Fe}_{3} \mathrm{O}_{4} @ \mathrm{Au}$ are not utilized in this work). Our calculations confirm that the property combination of the magnetic and plasmonic materials leads to the enhancement of the SPR-based biosensor sensitivity, which is applied to detect the existence of biomaterial samples such as blood plasma, $\mathrm{Hb}$ cytoplasm and lecithin as analytes. By varying the radii of the core $\left(\mathrm{Fe}_{3} \mathrm{O}_{4}\right)$ and the shell $(\mathrm{Au})$, the refractive index and the permittivity of the core-shell changes and leads to changes in the composite's (core-shell + biomaterial + water) permittivity. The SPR dip shifted to the right in the reflectivity spectra when the core-shell was added to the composite as the active material. This shift suggests the potential of the core-shell's inclusion to enhance the sensitivity of SPR biosensors, in this case for sensing biomaterial samples.

Author Contributions: Widayanti conceived the idea for the study, conceptualization, data curation, funding acquisition, methodology, software, visualization and writing original draft of the manuscript. Kamsul Abraha contributed to investigated, validated, writing-review \& editing draft of the manuscript and Agung Bambang Setio Utomo contribute to helped for supervision and validation. Kamsul Abraha as the corresponding author for this manuscript. All author contributed significant effort to the manuscript preparation.

Funding: This research received no external funding.

Conflicts of Interest: The authors declare no conflict of interest.

\section{References}

1. Stafford, S.; Garcia, R.S.; Gun'ko, Y.K. Multimodal Magnetic-Plasmonic Nanoparticles for Biomedical Applications. Appl. Sci. 2018, 8, 97. [CrossRef]

2. Agbor, N.E.; Cresswell, J.P.; Petty, M.C.; Monkman, A.P. An optical gas sensor based on polyaniline Langmuir-Blodgett films. Sens. Actuators B Chem. 1997, 41, 137-141. [CrossRef]

3. Kretschmann, E.; Raether, H. Notizen: Radiative Decay of Non Radiative Surface Plasmons Excited by Light. Z. Naturforsh 1968, 23A, 2135-2136. [CrossRef]

4. Liedberg, B.; Nylander, C.; Lunström, I. Surface plasmon resonance for gas detection and biosensing. Sens. Actuators 1983, 4, 299-304. [CrossRef] 
5. He, L.; Musick, M.D.; Nicewarner, S.R.; Salinas, F.G.; Benkovic, S.J.; Natan, M.J.; Keating, C.D. Colloidal Au-Enhanced Surface Plasmon Resonance for Ultrasensitive Detection of DNA Hybridization. J. Am. Chem. Soc. 2000, 122, 9071-9077. [CrossRef]

6. Milkani, E.; Lambert, C.R.; Mc Gimpsey, W.G. Direct detection of acetylcholinesterase inhibitor binding with an enzyme-based surface plasmon resonance sensor. Anal. Biochem. 2011, 408, 212-219. [CrossRef] [PubMed]

7. Salamon, Z.; Macleod, H.A.; Tollin, G. Surface plasmon resonance spectroscopy as a tool for investigating the biochemical and biophysical properties of membrane protein systems. II: Applications to biological systems. Biochim. Biophys. Acta 1997, 1331, 131-152. [CrossRef]

8. Sharma, A.K. Plasmonic biosensor for detection of hemoglobin concentration in human blood: Design considerations. J. Appl. Phys. 2013, 114, 044701. [CrossRef]

9. Wu, L.; Chu, H.S.; Koh, W.S.; Li, E.P. Highly sensitive graphene biosensors based on surface plasmon resonance. Opt. Express 2010, 18, 14395-14400. [CrossRef] [PubMed]

10. Liang, R.P.; Yao, G.H.; Fan, L.X.; Qiu, J.D. Magnetic $\mathrm{Fe}_{3} \mathrm{O}_{4} @ \mathrm{Au}$ composite-enhanced surface plasmon resonance for ultrasensitive detection of magnetic nanoparticle-enriched $\alpha$-fetoprotein. Anal. Chim. Acta 2012, 737, 22-28. [CrossRef] [PubMed]

11. Frasconi, M.; Tortolini, C.; Botrè, F.; Mazzei, F. Multifunctional Au Nanoparticle Dendrimer-Based Surface Plasmon Resonance Biosensor and Its Application for Improved Insulin Detection. Anal. Chem. 2010, 82, 7335-7342. [CrossRef] [PubMed]

12. Baida, H.; Billaud, P.; Marhaba, S.; Christofilos, D.; Cottancin, E.; Crut, A.; Lermé, J.; Maioli, P.; Pellarin, M.; Broyer, M.; et al. Quantitative Determination of the Size Dependence of Surface Plasmon Resonance Damping in Single Ag@SiO 2 Nanoparticles. Nano Lett. 2009, 9, 3463-3469. [CrossRef] [PubMed]

13. Zhu, J. Surface Plasmon Resonance from Bimetallic Interface in Au-Ag Core-Shell Structure Nanowires. Nanoscale Res. Lett. 2009, 4, 977-981. [CrossRef] [PubMed]

14. Pathak, N.; Ji, A.; Sharma, R.P. Tunable Properties of Surface Plasmon Resonances: The Influence of Core-Shell Thickness and Dielectric Environment. Plasmonics 2014, 9, 651-657. [CrossRef]

15. Ahmadi, N.; Poursalehi, R.; Farshi, M.K.M. The Interparticle Coupling Effect on Plasmon Resonance Properties of Magnetite@Au Magnetoplasmonic Nanoparticles. Procedia Mater. Sci. 2015, 11, $254-258$. [CrossRef]

16. Liu, Y.; Han, T.; Chen, C.; Bao, N.; Yu, C.M.; Gu, H.Y. A novel platform of hemoglobin on core-shell structurally $\mathrm{Fe}_{3} \mathrm{O}_{4} @ \mathrm{Au}$ nanoparticles and its direct electrochemistry. Electrochim. Acta 2011, 56, 3238-3247. [CrossRef]

17. Wang, J.; Song, D.; Zhang, H.; Zhang, J.; Jin, Y.; Zhang, H.; Zhou, H.; Sun, Y. Studies of $\mathrm{Fe}_{3} \mathrm{O}_{4} / \mathrm{Ag} / \mathrm{Au}$ composites for immunoassay based on surface plasmon resonance biosensor. Colloids Surf. B Biointerfaces 2013, 102, 165-170. [CrossRef] [PubMed]

18. Zhou, H.; Lee, J.; Park, T.J.; Lee, S.; Park, J. Ultrasensitive DNA monitoring by $\mathrm{Au}-\mathrm{Fe}_{3} \mathrm{O}_{4}$ nanocomplex. Sens. Actuators B Chem. 2012, 163, 224-232. [CrossRef]

19. Chen, H.; Qi, F.; Zhou, H.; Jia, S.; Gao, Y.; Koh, K.; Yin, Y. $\mathrm{Fe}_{3} \mathrm{O}_{4} @ \mathrm{Au}$ nanoparticles as a means of signal enhancement in surface plasmon resonance spectroscopy for thrombin detection. Sens. Actuators B Chem. 2015, 212, 505-511. [CrossRef]

20. Guo, X. $\mathrm{Fe}_{3} \mathrm{O}_{4} @ \mathrm{Au}$ nanoparticles enhanced surface plasmon resonance for ultrasensitive immunoassay. Sens. Actuators B Chem. 2014, 205, 276-280. [CrossRef]

21. Sharma, A.K.; Jha, R.; Pattanaik, H.S. Design considerations for surface plasmon resonance based detection of human blood group in near infrared. J. Appl. Phys. 2010, 107, 034701. [CrossRef]

22. Stuart, D.A.; Haes, A.J.; Yonzon, C.R.; Hicks, E.M.; Van Duyne, R.P. Biological applications of localized surface plasmonic phenomenae. IEE Proc. Nanobiotechnol. 2005, 152, 13-32. [CrossRef] [PubMed]

23. Jain, P.K.; Huang, X.; El Sayed, I.H.; El-Sayed, M.A. Review of some interesting surface plasmon resonance-enhanced properties of noble metal nanoparticles and their applications to biosystems'. Plasmonics 2007, 2, 107-118. [CrossRef]

24. Jin, Y.L.; Chen, J.Y.; Xu, L.; Wang, P.N. Refractive index measurement for biomaterial samples by total internal reflection. Phys. Med. Biol. 2006, 51. [CrossRef] [PubMed]

25. Johnson, P.B.; Christy, R.W. Optical Constants of the Noble Metals. Phys. Rev. B 1972, 6, 4370-4379. [CrossRef]

26. Rather, H. Surface Plasmons on Smooth and Rough Surfaces and Gratings; Springer: Berlin, Germany, 1986; ISBN 978-3-540-47441-8. 
27. Schlegel, A.; Alvarado, S.F.; Wachter, P. Optical properties of magnetite $\left(\mathrm{Fe}_{3} \mathrm{O}_{4}\right)$. J. Phys. C Solid State Phys. 1979, 12, 1157-1164. [CrossRef]

28. Chettiar, U.K.; Engheta, N. Internal homogenization: Effective permittivity of a coated sphere. Opt. Express 2012, 20, 22976-22986. [CrossRef] [PubMed]

29. Xue, Q. Effective-medium theory for two-phase random composites with an interfacial shell. J. Mater. Sci. Technol. 2000, 16, 367-369.

30. Verma, R.; Gupta, B.D.; Jha, R. Sensitivity enhancement of a surface plasmon resonance based biomolecules sensor using graphene and silicon layers. Sens. Actuators B Chem. 2011, 160, 623-631. [CrossRef]

(C) 2018 by the authors. Licensee MDPI, Basel, Switzerland. This article is an open access article distributed under the terms and conditions of the Creative Commons Attribution (CC BY) license (http:/ / creativecommons.org/licenses/by/4.0/). 